\begin{tabular}{lcc}
\hline & \multicolumn{2}{c}{ Observed decrease $(\mathrm{cm})$} \\
\cline { 2 - 3 } Age (years) & Women & Men \\
\hline 30 & 0.024 & 0.127 \\
40 & 0.410 & 0.596 \\
50 & 1.266 & 1.411 \\
60 & 2.592 & 2.572 \\
70 & 4.388 & 4.079 \\
80 & 6.654 & 5.932 \\
\hline
\end{tabular}

In any future screening for osteoporosis we intend to motivate people to attend by providing data on the rate of decrease in height of people in Busselton, particularly after the age of 40 . During 1966-81 serial examinations at three year intervals were conducted on nearly the entire adult population of Busselton; the heights of the 1785 women and 1544 men were measured on three to six occasions. No subject was excluded for health reasons. Random regression analysis of each person's height and age was used to estimate the expected rate of decrease in stature with age. ${ }^{3}$ Because the analysis was confined to longitudinal changes in individual people the secular trends were removed.

From the population data women's height was estimated to peak at $162 \cdot 1 \mathrm{~cm}$ at 26.8 years; for men the average maximum height was calculated to be $174.9 \mathrm{~cm}$ at 21.4 years. The table shows the observed decrease in height from peak stature in women and men at ages 30-80. It was concluded that men of predominantly northern European background could expect to be about $6 \mathrm{~cm}$ shorter than their peak height by the age of 80 , and women could expect to be $6 \cdot 7 \mathrm{~cm}$ shorter. Such information may be a motivation to attend screenings for osteoporosis.

PO Box 126,

Busselton,

Western Australia 6280

Australia

1 Garton MJ, Torgerson DJ, Donaldson C, Russell IT, Reid DM. Recruitment methods for screening programmes: trial of a
new method within a regional osteoporosis study. $B M J$ new method within a

2 Curnow DH, Cullen KJ, McCall MG, Stenhouse NS, Welborn TA. Health and disease in a rural community: a Western Australian study. Australian foumal of Science 1979;31:281-5.

3 Chandler PJ, Bock RD. Age changes in adult stature: trend estimation from mixed longitudinal data. Ann Hum Biol 1991;18:433-40.

\section{Human insulin and unawareness of hypoglycaemia}

EDIToR, - The three articles on loss of awareness of hypoglycaemia with human insulin in a recent issue give the general impression that there is not really a problem with human insulin ${ }^{1.3}$ Certainly all the research that has been done has not given a definitive answer, but it does suggest that there may be a problem in certain studies. Nobody, however, seems to have taken any account of what diabetic patients are saying.

I have had insulin dependent diabetes for 23 years and have taken human insulin for two periods of two and a half years each. I found human insulin awful, and my control has been much better since I resumed taking porcine insulin. I know of other diabetic patients who have felt the same, but nobody really listens or thinks that diabetic patients' opinions are of any great value. Doctors ignore this at their peril.

John E Gerich quotes the recent study by Colagiuri et al in Australia as being some form of benchmark in research into this problem. ${ }^{+}$This study has two serious flaws in its design. Firstly, being in a study makes diabetic patients control their disease better than they do in normal daily life. This and the fact that the patients were put on to human or porcine insulin for only one month at a time in the study, albeit under double blind conditions, mean that it is not surprising that the patients could not tell which insulin they were receiving. If they had received each type of insulin for six months or a year they might have been able to tell the difference.

This leads me to the second flaw in the study. Colagiuri et al say that the patients they took for the study had complained that they had lost their symptoms of hypoglycaemic awareness. If this is so it is common sense to assume that somebody elseprobably a family member or close work colleague -made the patients aware of this fact; but the questionnaires were completed only by the patients themselves with no input from the family members who would have been the first to notice whether the patients had lost their awareness.

I disagree vehemently with Gerich when he says that a study should be conducted along these lines. If it is it will be worthless as well.

Paxton Green Health Centre,

M R KILN

Pondon SE21 8AU

1 Gerich JE. Unawareness of hypoglycaemia and human insulin. BM7 1992;305:324-5. (8 August.)

2 Egger M, Smith G, Teuscher A. Human insulin and hypoglycaemic unawareness: on the need for a large randomised trial. BMF 1992;305:351-5. (8 August.)

3 Williams G, Patrick A. Human insulin and hypoglycaemia burning issue or hot air? BMF 1992;305:355-7. (8 August.)

4 Colagiuri S, Miller J, Petocz P. Double-blind crossove comparison of human and porcine insulin in patients reportin lack of hypoglycaemia awareness. Lancet 1992;339:1432-5.

\section{Fluid replacement in diabetic ketoacidosis}

EDIToR,-If, as Peter Hammond and Simon Wallis suggest, emphasis is to be given to preventing the development of cerebral oedema in diabetic ketoacidosis ${ }^{1}$ we need a careful analysis of the optimal levels of fluid replacement. My clinical and anecdotal impression is that the pattern of presentation of ketoacidosis is changing. Either because of newer insulins or, more probably, because of the newer regimens of insulin delivery patients are presenting earlier, with severe acidosis yet not necessarily severely dehydrated. I believe that overzealous fluid replacement in these cases may be potentially, and at worst is definitely, harmful. In patients who are haemodynamically stable I adopt an initial rate of fluid replacement of $2-3 \mathrm{ml} / \mathrm{kg} / \mathrm{h}$, which is well below that recommended in recently published textbooks. ${ }^{2}$ Problems have arisen only when doctors have not followed the local protocol.

Experimental proof of this hypothesis is difficult, but support for lower rates of fluid replacement is increasing. ${ }^{34}$ Diabetic ketoacidosis carries a significant mortality, ${ }^{2}$ much greater than that from hypoglycaemia. Improvements in its management will be achieved only by careful audit of cases. In addition, I think that there is sufficient doubt about the necessity and safety of using the currently recommended initial rates of fluid replacement that a carefully controlled study needs to be performed. This will not be easy and by necessity will need to be a multicentre study, but the cardiologists have shown us the way. It is time for the diabetologists and British Diabetic Association to grasp the nettle.

Department of Diabetes and Endocrinology, COLIN JOHNSTON

Hemel Hempstead General Hospital,

Hemel Hempstead, Hertfordshire HP2 4AD

1 Hammond $\mathrm{P}$, Wallis $\mathrm{S}$. Cerebral oedema in diabetic ketoacidosis BMF 1992;305:203-4. (25 July)

2 Dornan T. Ketoacidosis and hyperosmolar coma. In: Tattersal RB, Gale EAM, eds. Diabetes clinical management. Edinburgh Churchill Livingstone, 1990:214-27.
3 Androgue HJ, Barrero J, Eknoyan G. Salutary effects of modest fluid replacement in the treatment of adults with diabetic ketoacidosis. FAMA 1989;262:2108-13.

4 Duck SC, Wyatt DT. Factors associated with brain herniation in the treatment of diabetic ketoacidosis. I Pediatr 1988;113: $10-4$.

5 Tunbridge WMG. Factors contributing to deaths of diabetics under fifty years of age. Lancet 1981;ii:569-72.

\section{Poisoning and child resistant containers}

EDITOR,-Minerva's extract from the Fournal of Epidemiology and Community Health says that the credit for the reduction in childhood poisoning cannot go to the introduction of child resistant containers because they came into general use in 1981 and "the admission rates for poisoning with substances not in safe containers, such as berries, plants, and mushrooms, have fallen more than for poisoning with drugs."'

This cannot be allowed to go unchallenged. In drawing a comparison between two methods of prevention it is important to limit methodological differences - in this case the use of child resistant containers. Before these containers were introduced in 1976 for aspirin and paracetamol sold over the counter for children some 7000 children were admitted to hospital with poisoning annually. These drugs sold over the counter for adults were packaged in child resistant containers the next year, and by the end of 1978 the number of children admitted with poisoning had fallen to below 2000. Admission of children from drugs not in child resistant containers had, however, remained unchanged. ${ }^{2}$ So far as we are aware, the only difference between the two groups was the packaging of the drugs. If the authors of the paper can tell us of any other measures that have reduced the admissions of children to hospital by 5000 a year we would be glad to hear of it.

There is another misleading statement in the paper. Though child resistant containers. "came into general use" in 1981, this was by voluntary arrangement, and they were not used anywhere near as widely as had been hoped. It is not surprising, therefore, that the rate of poisoning from drugs did not fall rapidly. The Royal Pharmaceutical Society has therefore now made it a professional requirement that child resistant containers or strip or blister packs must be used unless the recipient specifically requests otherwise.

Of course, several other factors need to be taken into account in considering the numbers of children admitted to hospital with poisoning. Poisoning from berries and so on may be less common than previously as a result of education or the criteria for admission may be stricter than formerly, or both. We remain convinced, however, that use of child resistant containers has been one of the most effective ways of preventing accidents yet introduced.

R H JACKSON A W CRAFT

Children's Department,

Royal Victoria Infirmary,

Newcastle upon Tyne NE1 4LP

1 Minerva. BMF 1992;305:128. (11 July.)

2 Jackson RH, Craft AW, Lawson GR, Beattie AB, Sibert JR. Changing patterns of poisoning in children. $B M \mathcal{T}^{1}$ 1983:287: 1468

\section{Health service support of breast feeding}

EDITOR,-Sally Beeken and Tony Waterston note the wide discrepancy between hospital policy and practice in the establishment and continuation of breast feeding in Newcastle upon Tyne. ${ }^{1}$ Such a discrepancy was also evident in a study I carried out in Fife Health Board last year. There the 
Practices associated with continuation of breast feeding beyond 10 days. Figures are numbers (percentages) of mothers

\begin{tabular}{lcc}
\hline & Breast fed for $\leqslant 10$ days $(\mathrm{n}=27)$ & Breast fed for $>10$ days $(\mathrm{n}=109)$ \\
\hline & $(\mathrm{n}=27)$ & $(\mathrm{n}=107)$ \\
Baby fed on demand & $12(44)$ & $89(83)$ \\
Baby fed at set times & $15(56)$ & $18(17)$ \\
& $\chi^{2}=15 \cdot 4, \mathrm{df}=1, \mathrm{p}<0.0001$ & $(\mathrm{n}=106)$ \\
Baby breast fed only & $(\mathrm{n}=26)$ & $63(59)$ \\
Baby given supplementary bottle & $5(19)$ & $43(41)$ \\
& $21(81)$ & $(\mathrm{n}=109)$ \\
Baby put to breast within 1 hour & $(\mathrm{n}=27)$ & $69(63)$ \\
Baby put to breast after 1 hour & $10(37)$ & $40(37)$ \\
& $17(63)$ & \\
Baby not "roomed in" with mother & $\chi^{2}=11 \cdot 95, \mathrm{df}=1, \mathrm{p}<0.001$ & \\
\end{tabular}

incidence of breast feeding was low and the duration short: $40-44 \%$ of mothers were breast feeding on the tenth day of each month in the second half of 1989 .

In January and February 1991 I used a structured questionnaire to interview 257 of the 276 mothers who had given birth in Fife during the last three weeks of November 1990. This was to find out factors relevant in their decisions to choose and to continue to breast feed in order to promote the practice. Of the 136 mothers who had started to breast feed, 27 had stopped by the tenth day after the birth.

The survey showed that practices out of line with current policy were taking place in hospitals in Fife. In addition, although sample sizes were small, I found that most of these practices were significantly associated with breast feeding for 10 days or less. These were late initiation of breast feeding (more than an hour after the birth), giving supplementary bottles while breast feeding, and feeding at set times (table).

Beeken and Waterston emphasise the importance of attitudes of health professionals who supervise and support breast feeding mothers and, in particular, of the need "to increase their awareness of breast feeding issues, promotion, and management." In an attempt to do that the joint breast feeding initiative was launched in Fife with a seminar on breast feeding in September 1990. A breast feeding steering group, comprising hospital staff, health visitors, and voluntary counsellors, meets regularly to discuss current issues. Defects found in the study are being rectified. More opportunities for such interdisciplinary communication would aid the implementation of Unicef's code of practice for baby friendly hospitals $^{2}$ and may help us to practise what we preach. SARAH P WILLIAMS

Cambridge University School of Clinical Medicine, Addenbrooke's Hospital,

Cambridge CB2 2QQ

1 Beeken S, Waterston T. Health service support of breast feeding - are we practising what we preach? BMF 1992;305: 285-7. (1 August.)

2 Grant J. State of the world's children 1992. New York: Unicef, Oxford University Press, 1992.

EDITOR,-Establishing successful breast feeding depends not only on hospital policy and technique but on acquiring skills to maintain breast feeding in the home. I recently did a study on antenatal education and found that 45 of 200 mothers whose infants were less than 3 weeks old were not breast feeding, although they had expressed a desire to breast feed. Some of the challenges facing a breast feeding mother, often before breast feeding is fully established, are dealing with embarrassed relatives and visitors, male and female; dealing with inappropriate advice, whether requested or not; dealing with physical discomfort; and dealing with a small crying infant.

Though codes of practice can be improved in some maternity hospitals by improving techniques and implementing policy, as Sally Beeken and Tony Waterston suggest,' the designation of "baby friendly hospital" should be awarded to those hospitals that help parents to cope with breast feeding in the social setting of their home, which many mothers believe is not currently addressed.

Health Promotion and Education Centre, ANN WYLIE

Tilehurst,

Berkshire RG3 4EJ

1 Beeken S, Waterston T. Health service support of breast feeding -are we practising what we preach? BMF 1992;305: 285-7. (1 August.)

EDITOR,-Sally Beeken and Tony Waterston's paper on attitudes to breast feeding has important implications for hospital policy, ${ }^{1}$ and the code of practice for "baby friendly hospitals" should be enshrined in contract specifications to provider units. ${ }^{2}$ When "training all health care staff (hospital ment this policy"' provider units should take into account the communication problems and cultural differences of Asians and other ethnic groups.

In 1991 a questionnaire survey of attitudes to breast feeding among 35 Asian Muslim mothers from child health clinics in South Birmingham Health Authority found that 21 of the women required an interpreter to help them communicate in English. Although 25 of the mothers had put the baby to the breast at least once by 2 weeks, only 16 attrition in the first two weeks than that reported by the Office of Population Censuses and Surveys in $1985 .{ }^{3}$ All the women who had given up would ideally have liked to have continued breast feeding and thought that that was the best way to feed a baby.

When asked whom they turned to for advice on feeding none of the women mentioned their community midwife despite her frequent visits during that period, and only two mentioned their health visitor. Most of the women who had given up did not speak English; this highlights the communication problems of health professionals who are trying to support women during this period. The Spitalfields infant feeding project showed that providing a worker who can give mothers information and support in their own language once they are at home can have a considerable effect on the continuation of breast feeding. ${ }^{4}$

All units need adequate numbers of linkworkers or interpreters to be available in maternity wards, antenatal clinics, and the community at all times for this code of practice to succeed. The needs of ethnic groups should be considered when hospital or community breast feeding counsellors are appointed.

Department of Public Health Medicine,

North Tees Health Authority,

Stockton on Tees,

Stockton on Tees,
Cleveland TS19 0EA and community) in the skills necessary to implewere breast or mixed feeding - a higher rate of

JANET STEVENSON
I Beeken S, Waterston T. Health service support of breast feeding - are we practising what we preach? BMf 1992;305: 285-7. (1 August.)

2 Grant J. State of the world's children 1992. New York: Unicef, Oxford University Press, 1992:44.

3 Martin J, White A. Infant feeding 1985. London: HMSO, 1988. 4 Hilder L. Infant feeding project report. London: Tower Hamlets Maternity Services Liaison Scheme, 1989.

EDITOR,-Sally Beeken and Tony Waterston report an unhelpful and muddled attitude of midwives and health visitors to breast feeding despite a campaign on breast feeding aimed at health care professionals. ${ }^{1}$ Many breast fed babies were given additional water or formula feeds. Thirty three of 50 mothers who answered a questionnaire had been separated from their babies for the first night.

The authors are unclear and obviously puzzled about the reasons for the professionals' ambivalence to breast feeding. They suggest a possible fear "of making bottle feeding mothers feel guilty or inferior"; there is some truth in this hypothesis. The mothering that a woman has had affects how she cares for her child. Changing attitudes to childrearing involve understanding how we feel about the way our mothers cared for us. Feeding a baby differently from the way we were fed means making implicit or explicit judgments on our own mothers; so midwives and health visitors are uncomfortable about making the mother they have in their minds feel guilty or inferior.

A contented mother with her satisfied baby at the breast can provoke desires in caring professionals to be cared for and nurtured. If unacknowledged this desire to be looked after may get in the way of our being able to provide the conditions that we know to be optimal.

The attitudes of staff towards sensitive subjects like breast feeding are difficult to change by exhortation. Discussions in small groups led by suitably trained staff are necessary. Regular discussion helps to prevent rigid positions developing on sensitive issues. The provision of nurseries that facilitate separation of the mother from her healthy neonate born in hospital reminds us of the struggle to get staff to allow mothers to see and hold their stillborn child; this change in attitudes to a flexible approach has required continuing group discussions.

EMANUEL LEWIS ELIZABETH BRADLEY

Tavistock Clinic,

London NW3 5BA

1 Beeken $S$, Waterston $T$. Health service support of breast feeding - are we practising what we preach? BMf 1992;305: 285-7. (1 August.)

\section{Early parenteral penicillin in meningococcal disease}

EDIToR,- Jeffrie R Strang and Edwin J Pugh' ${ }^{1}$ and Keith Cartwright and colleagues ${ }^{2}$ have studied the effect on outcome of giving penicillin before admission to hospital in suspected cases of meningococcal disease. We have looked at the early use of antibiotics in Worcester district, where there is a higher than average incidence of meningococcal disease $(10 \cdot 2$ cases/100 000 population in 1991$)$.

We have retrospectively studied cases of meninococcal disease reported to Worcester and District Health Authority from 1 January 1986 to 30 June this year. Of 121 recorded cases, 109 have been evaluated by review of medical case notes and the general practitioner's admission letter. In each case meningococcal disease was diagnosed on the basis of one or more of the following criteria: (a) Neisseria meningitidis isolated from blood or cerebrospinal fluid, or both; $(b)$ Gram negative diplococci seen on microscopic examination of cerebrospinal fluid; $(c)$ a rise in serum meningo- 